\title{
The Performance of Notes Inégales: The Influence of Tempo, Musical Structure, and Individual Performance Style on Expressive Timing
}

Dirk Moelants

Ghent University, Ghent, Belgium

NOTES INÉGALES IS A COMMON PRACTICE IN THE performance of French baroque music. It indicates that the first of a pair of equally notated notes is played longer, similar to the use of swing eighths in jazz. The performance of that inequality is an ongoing source of debate, but the actual performance has not been studied yet. In an experiment, eight harpsichordists and eight baroque violinists performed six melodies of French baroque gavottes in three tempo conditions. The mean ratio of inequality was 1.63 , with mean ratios of individual performers varying between 1.89 and 1.33. Another significant source of variance was the metric structure, with larger inequality found at metrically important points. Tempo also had an important influence, but individual interpretation varied greatly. For example, while most performers played more evenly while tempo increased, some performers chose the opposite strategy. Pitch interval had only a minor impact on the execution of the notes inégales, but also showed differences between performers. The results show the importance of personal style in music performance: although the music played is highly standardized, we show how the timing of different performers can be influenced by different aspects of the musical structure.

Received February 2, 2010, accepted October 14, 2010.

Key words: rhythm, tempo, performance, baroque music, swing

\section{$N$} OTES INÉGALES, OR UNEQUAL NOTES, IS A KEY concept in the performance of (French) baroque music. It indicates that two successive short notes should be performed with unequal duration, even though they are notated with equal rhythmic values. In standard historical performance practice, the first note in a pair must be elongated at the expense of the second, but occasionally the opposite is requested.
This is always made in explicit verbal instructions (notes coulés). The practice of inégalité is extensively discussed in treatises from the 16th to the 18th century (see Borrel, 1931; Fuller, 2001; Hefling, 1993). Explicit indications that certain passages should not be played inégale include markings such as notes égales, détaché, dots placed over the note heads, or directives concerning the treatment of larger interval leaps, which are also typically to be performed with even timing (e.g., Couperin, 1716/1974).

Unequal performance timing usually applies to the metric level that lays two levels below the main (or tactus) beat in duple meter, and one level below the main beat in triple meter. Thus, it generally applies to eighth notes and sometimes to sixteenth notes; for example, in allemandes and other movements clearly written in $4 / 4$ meter (Hefling, 1993).

The main problem in the interpretation of notes inégales is in the determination of the amount of inequality, the ratio between the longer and the shorter note in the pair. Performers with a background in "historically informed" performance practice would commonly prefer to find ratios as close as possible to the intentions of the composer. However, historical sources are usually quite vague and sometimes even contradictory. Apparently, it was impossible (or simply impractical) for the composers to notate the exact rhythmic division they wanted (Byrt, 1996). Also, instructions in historical treatise are seldom very precise. Loulié (1696) illustrated the performance of notes inégales with a dotted eighth note followed by a normal eighth note, thus suggesting a 3:2 (1.5) ratio. Other sources, however, suggest a dotted 3:1 ratio, while most sources remain vague, asking the performer to play the first note "a little bit longer" (Hefling, 1993). One source that has gained particular interest in the study of inégalité (Houle, 1987; Schmitz, 1953) is Engramelle's (1775/1993) "La tonotechnie." This is a work that mainly deals with the technique of pinning for mechanical organs. Although it was written significantly later than the pieces studied here, it gives a clear and precise illustration of how inequality can be realized practically. In this work, ratios ranging from 3:1 to 9:7 (1.29) are found. Engramelle also notes that the inequality should be stronger in gay tunes,

Music Perception volume 28, issue 5, Pp. 449-460, isSN 0730-7829, ELECTRONIC ISSN 1533-8312 @ 2011 By THE REGENTS OF THE UNIVERSITy OF CALIFORNIA. ALL RIGHTS RESERVED. PLEASE DIRECT ALL REQUESTS FOR PERMISSION TO PHOTOCOPY OR REPRODUCE ARTICLE CONTENT THROUGH THE UNIVERSITY OF CALIFORNIA PRESS'S RIGHTS AND PERMISSIONS WEBSITE, HTTP://WWW.UCPRESSJOURNALS.COM/REPRINTINFO.ASP. DOI:10.1525/MP.2011.28.5.449 
compared to tender ones, and that the ratios may vary within the same piece. This source has the benefit of reflecting actual performance practice, beyond the purely theoretical treatises that suggest a more constant ratio.

While the use of inégalité in France is still relatively well documented and its importance is widely recognized by both scholars and performers, its use outside France (and specifically in works of Bach and Händel) is more controversial and has been the subject of many scholarly debates (Babitz, Byrt, \& Collins, 1967; Byrt, 2007; Donington, 1967; Fuller, 2001; Hefling, 1993; Neumann, 1965, 1988; Newman, 1985).

Traditional musicological research has focused on the study of original sources. Research in music performance has shown much less interest in notes inégales. The related phenomenon of overdotting was investigated by Fabian and Schubert (2003), analyzing Bach performances. Ornoy (2006) studied a number of parameters in performances of some works by Bach and Scarlatti, mainly looking for what distinguishes historically informed performers from others. Although he found notes inégales in the historically informed performances, it must be noted that he did not analyze any French music and did not give details about the ratios.

For a related phenomenon that has been studied extensively, we have to leave the world of early music for jazz. Here, the characteristic long-short subdivision is called swing. Several authors have conducted empirical studies on the timing of the swing ratio (Collier \& Collier, 1996; Friberg \& Sundberg, 2002; Honing \& De Haas, 2008; Prögler, 1995). Therefore, comparison between the two phenomena could prove useful in the study of notes inégales. It should, however, be noted that research on jazz swing has focused on drummers, who usually perform an ongoing long-short-short pattern in which they delay the last short note. In the present study the inequality occurs both on strong and weak beats, but is sometimes interrupted by longer notes.

In more general terms, it is well known that increasing the interonset interval after metrically important notes is a technique used by musicians to emphasize the metrical structure (e.g., Palmer, 1997; Sloboda, 1983). In music practice, this technique is mixed with other methods of accentuation, such as playing important notes louder or postponing their attack. Therefore, temporal lengthening is usually not applied consistently throughout. The rule of notes inégales can thus be interpreted as an instruction to emphasize the metric structure by lengthening metrically important notes.

The present study investigates how the timing of notes inégales is performed by contemporary performers, with a background in historical performance practice. It focuses on the influence of musical structure (tempo, meter, pitch intervals) and the personal interpretation of the individual performers.

\section{Method}

Sixteen performers specialized in the (historically informed) performance of baroque music were asked to perform a number of fragments taken from original sources. The examples were taken from gavottes, a dance movement that usually contains series of eighth notes that should be performed inégale. In order to avoid the influence of differences in tempo and of tempo rubato, performers were asked to play with a metronome at three different tempi. This allows researchers to examine the influence of tempo on timing (cf. Honing, 2006), and it is musically valid because of the lack of a characteristic tempo for the gavotte. Rousseau (1772), for example, writes, "Le mouvement de la gavotte est ordinairement gracieux, souvent gai, quelquefois aussi tendre et lent" [The movement of the gavotte is usually graceful, often gay, but sometimes also tender and slow ]. An extra verbal tempo indication was added when a composer wanted to impose a certain character. Examples vary between indications associated with slower tempi such as tendrement (tenderly) and indications that point at fast tempi such as gaiement (joyfully).

\section{Subjects}

Eight baroque violinists and eight harpsichordists participated in the experiment. All subjects were either professional musicians $(N=9)$ or master-level conservatory students with experience in the professional music world $(N=7)$. Their ages ranged from 23 to 64 , with a mean of 36.4. Eight were male and eight were female. All participants were trained in the performance of baroque music and had knowledge of, and experience with, the performance of French baroque music at a professional level.

Music

Six melodies were selected from French gavottes, composed around 1700. The gavotte is originally a French folk dance, which was adapted as a court dance starting in the late 16th century (Arbeau, 1588). It is related to the branle, which was popular in the 16th century and was gradually replaced by the gavotte during the 17th century. Gavottes are binary dances, usually written in $2 / 2$ meter, with a half-measure upbeat. They are considered 

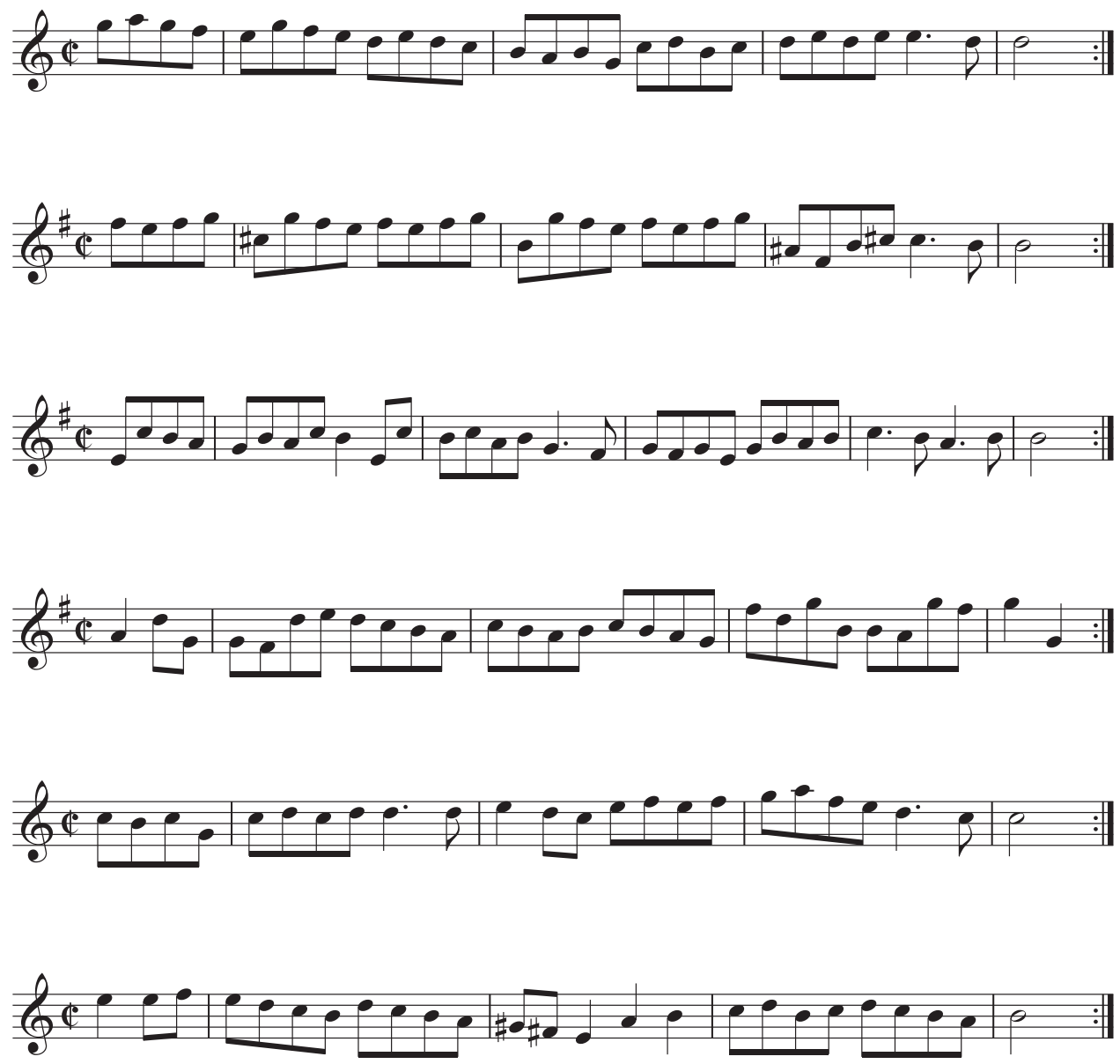

FIGURE 1. The six gavotte melodies used in the experiment. Each melody was played with repeat, in the three different tempo conditions.

to be relatively simple in their metric structure, and often contain eighth notes that should be performed inégale (Little, 2001).

The experimental excerpts were taken from compositions by Louis-Nicolas Clérambault (Gavotte-Double from the "Premier Livre de Pièces de Clavecin," 1704), François Couperin (Gavotte, gracieusement, sans lenteur from the "Suite no. 1 pour Viole et Basse Chiffrée," 1728), Gaspard Le Roux (Gavotte in a-minor from the "Premier Livre de Pièces de Clavecin," 1705), Marin Marais (Gavotte-Double in D-major from the "Pieces en Trio pour les Flutes, Violon et Dessus de Viole," 1692), Joseph Bodin de Boismortier (Gavotte en rondeau in e-minor from Diverses Pieces de Viole avec la Basse chiffrée," 1730), and Roland Marais (Gavotte-Double in e-minor from the "Premier Livre de Pieces de Viole Avec la Basse chifrée," 1735). In every case, only the main melody line was retained, in order to make performance on the violin possible. If necessary, the pieces were transposed an octave higher for the same reason. The notation was standardized, and all extra notation elements (e.g., articulation marks, ornaments) were removed (see Figure 1). To avoid effects of familiarity, the selected pieces did not belong to the standard repertoire for violin or harpsichord. After completing the experiment, performers were asked if they were familiar with any of the fragments. No subjects reported any familiarity with any of the fragments. Another element that was taken into account in making the selection of pieces was the technical level; selected excerpts were chosen to avoid confounding factors related to technical problems that might interfere with the musical expression. Each of the fragments consists primarily of pairs of eighth notes that should be played inégale. Pitch intervals were generally small, but a few larger leaps were included, in order to test the influence of pitch interval on the performance timing, in particular to see if these larger leaps are performed equally as suggested by Couperin (1716/1974) and other historical sources. 


\section{Procedure}

Musicians were invited to participate by e-mail. When they agreed to participate in the experiment, an appointment was made and they received an e-mail with the score, background information of the study, and instructions written in Dutch, French, and English. Explicit instructions were distributed to participants:

"Herewith, six fragments from French gavottes, composed in the late 17th or early 18th century. Characteristic for this music is that it should be performed with so-called 'notes inégales.' This means that for every pair of eighth notes, the first is played longer than the second. With this study we want to find out how experienced musicians use this 'inégalité' in practice. What are the ratios between the notes, are they constant or is there a lot of variability, which structural elements influence these variations (e.g., meter, pitch interval or direction...), are there differences between individual performers, what is the influence of the global tempo...? We want to find the answers to these questions in order to gain insight into contemporary performance practice of French baroque music.

Each of the six excerpts is to be played four times (always including repeat).

1. in a free tempo

2. with a metronome in a slow tempo $(\mathrm{MM}=40$ at the half measure level)

3. with a metronome in a moderate tempo $(\mathrm{MM}=60$ at the half measure level)

4. with a metronome in a fast tempo $(\mathrm{MM}=80$ at the half measure level)

Always play expressively, also in the metronome conditions. Don't think too much about how to perform the 'notes inégales,' but make sure the music sounds natural, following your own 'bon goût."'

Recordings were made with Aevox Classic M MkII stereo microphones connected to an M-Audio Microtrack $24 / 96$ and stored in $44.1 \mathrm{kHz}$.wav format. The microphones were placed on a stand, just above the violin or the jacks of the harpsichord, in order to record a clear and direct sound. The recordings were made at places familiar to the performers at their homes, schools, or rehearsal places, so each of the musicians could use his/ her own instrument or at least a familiar instrument. Metronome ticks were generated by a Wittner MT-50 metronome and presented to the players through Sennheiser HD 215 headphones to avoid recording the metronome ticks.

The first recording session (free tempo) was not analyzed in detail. Rather, it was considered a trial session, which was also an opportunity for feedback. Thus, for example, some performers spontaneously added some ornaments or did not keep a constant position to the microphone. A global view on the tempi used in this free session shows an average tempo of $70 \mathrm{bpm}$, with a standard deviation of 9.9. Thus, most players chose tempi between the medium and fast tempo conditions used in the actual experiment.

\section{Analysis}

The performances were analyzed manually using the program Praat (Boersma \& Weenink, 2008). The onsets were first localized using a combination of the graphical representation of the sound wave and the analyses of pitch and dynamics given by Praat. Probable onsets were determined from the graphical representations, checked aurally by playing the parts before and after this preliminary onset separately, and positions were adjusted accordingly. For the harpsichord recordings, this method proved accurate, as the onsets have a very clear, short rise time. Identifying the onset of violin tones is more interpretive, as the pitch slowly develops after the physical onset. As interval timing was the factor under consideration, it was important to apply the same cue for the determination method for all onset locations. For this reason, we chose to indicate the start of the small noise burst that accompanies the physical onset of a baroque violin tone. This element is present in all tones and is easy to locate precisely by ear.

From the onset points, performed note lengths were calculated, as well as the ratio between successive notes. From the note lengths, we can also extrapolate the beat lengths. As the participants performed with a metronome, significant variation at the half-note level did not occur. More surprisingly, variation at the quarter-note level was also not significant. As significantly different timing values were not found between the quarter-note beats at any of the three tempi, this aspect will not be discussed in further detail. The ratio between the notes inégales (an eighth note on the beat and the following off-beat eighth-note) will, as a result, be the main dependent variable used in this study. Music scores were also analyzed, listing the pitch, pitch intervals, note length, and metric position for each note. The pitch intervals between the two notes of the inégale pairs were classified in four classes: minor seconds $(N=$ 34 ), major seconds $(N=68)$, thirds (major + minor; $N=$ $16)$, and intervals larger than a third $(N=14)$.

\section{Results}

The global ratio of inequality was $1.63(S D=0.39)$, which is close to a 5:3 ratio. The ratio decreased when 
tempo increased with an average ratio of 1.68 at $\mathrm{MM}=$ $40,1.61$ at $\mathrm{MM}=60$, and 1.60 at $\mathrm{MM}=80, F(2,6429)=$ $32.32, p<.001$. The influence of pitch interval showed a global increase of the ratio with larger intervals, with averages of 1.61 for semitone intervals, 1.63 for whole tone intervals and thirds, and 1.69 for larger intervals, $F(3,6428)=6.79, p<.001$. Descending intervals $(M=$ $1.62)$ were performed slightly less unequal than ascending intervals $(M=1.65), F(1,6430)=8.27, p<.01$. The influence of the position in the measure showed much stronger inequality on the strong quarter note beats than on the weaker ones: 1.76-1.49-1.79-1.51 mean ratios for the four successive pairs of eighth notes in the measure, $F(3,6428)=308.12, p<.001$. However, the differences between performers were especially striking, with averages ranging from 1.33 to $1.89, F(15,6416)=103.14$, $p<.001$. It was, therefore, necessary to examine the individual interpretations, rather than the global effects when analyzing timing variation.

First, we examined the overall results of the individual subjects (Figure 2). In addition to the large differences in mean ratio, the within-subject variance also varied substantially, with standard deviations between 0.17 and 0.50 . $T$-tests showed no significant influence of gender or instrument on the ratio or its standard deviation. In addition, a new parameter was computed to give an idea about the fame of the participants. The number of hits scored by searching for their full name in the Google.com search engine was used (in a few cases a manual check had to be done to separate the participants from people with the

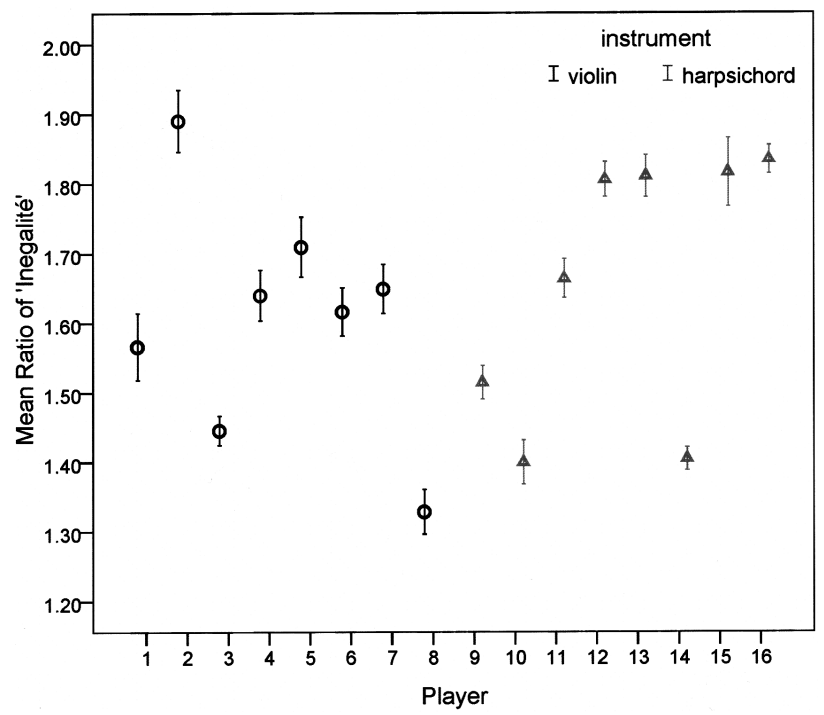

FIGURE 2. Mean ratio of inégalité shown for each performer with the $95 \%$ confidence interval of the mean. The first eight (darker marks, circles) are violinists; subjects 9-16 (lighter marks, triangles) are harpsichordists. same name). The minimum was 5 , the maximum 111,000 , with the median at 40 . If we use this parameter to divide the participants into two groups, it coincides with a division according to age (median 38.5). However, this "age-fame" parameter does not show a significant influence on the inégalité ratio and its standard deviation.

Analysis of variance was performed on the ratios of the 16 individual participants to look for effects of tempo and structural elements. Fourteen of the subjects showed a highly significant effect of main tempo on the ratio. With $F(2,399)$ ranging between 4.64 and 77.08 , the effect was significant at a $p<.01$ level for three players and at a $p<.001$ level for the other 11 players. For two subjects there was no significant effect. The general tendency was to decrease the ratio when tempo increased, as was observed in a majority of the individual performers' results. However, if we look at Figure 3, we see that the situation is more complicated and that differences between players are large. Players 4 and 9 did not show a significant effect of tempo. Players 1, 2, 7, 11, 14 \& 15 show a gradual decrease with increased tempo, but players 5 and 10 show the exact opposite tendency, increasing the inequality ratio when tempo increased. The other performers showed more significant differences between one tempo category and the other two. Player 3 used a larger ratio with $M M=80$, while players 6 and 12 use smaller ratios at this tempo. Players 8,13 , and 16 used larger ratios at $\mathrm{MM}=40$ compared to the faster tempi. Some performers demonstrated very large differences in their ratio according to the tempo; for others, we found a small, but consistent change. Player 2, with ratios of $2.21(S D=0.43)$ at $\mathrm{MM}=40,1.82(S D=0.40)$ at $\mathrm{MM}=60$, and $1.64(S D=0.33)$ at $\mathrm{MM}=80$, produced

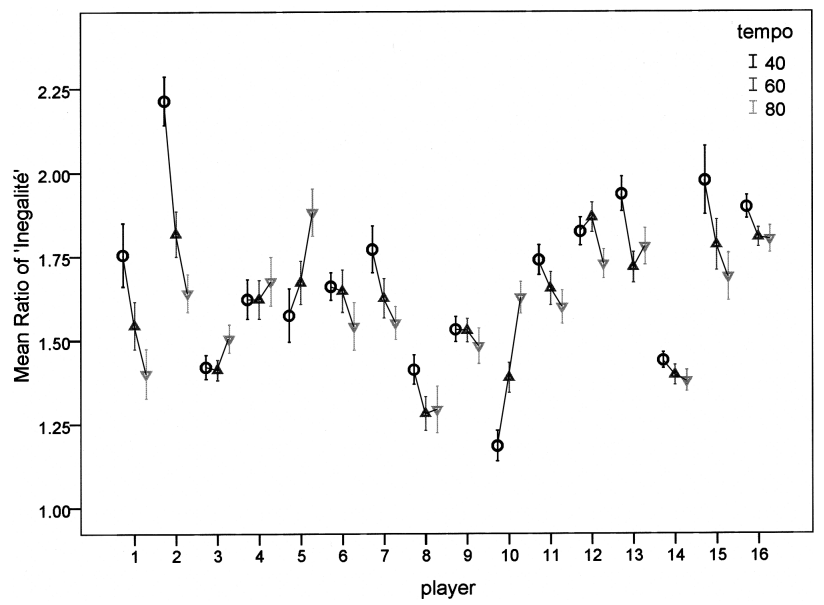

FIGURE 3. Mean ratio of inégalité shown for each performer at each of the three base tempi; error bars represent the $95 \%$ confidence interval of the mean. 
greater differences in ratio, but still varied quite a lot within each tempo. Player 8 , on the contrary, produced only a small difference in the mean ratio but with a very small variability: ratio $1.44(S D=0.14)$ at $\mathrm{MM}=40$, $1.40(S D=0.17)$ at $\mathrm{MM}=60$, and $1.38(S D=0.19)$ at $M M=80$. The player who showed the strongest effect of tempo was Player 10 with ratios of $1.18(S D=0.27)$ at $\mathrm{MM}=40,1.38(S D=0.26)$ at $\mathrm{MM}=60$, and $1.63(S D=$ $0.28)$ at $\mathrm{MM}=80$. This is especially notable as it contradicted the main tendency to diminish the ratio with increased tempo.

To investigate the effect of metric position, we compared ratios between pairs of eighth notes that fell on the first $(N=34)$, second $(N=34)$, third $(N=30)$, and fourth $(N=36)$ quarter of the measure. Only one participant (16) did not show a significant effect of metric position; for all others, the effect was highly significant at a $p<.001$ level, with $F(3,398)$ ranging from 6.84 to 121.76. As shown in Figure 4, the performers largely agree on the main tendency to use larger ratios on strong quarter note beats (corresponding to the pairs starting with the 1st and 5th eighth note in the measure) and smaller ratios on the weak beats (the pairs starting with the $3 \mathrm{rd}$ and 7 th eighth note in the measure). Differences between performers were mainly found in the amount of change in mean ratio between strong and weak beats. While some players (e.g., player 12) only made a subtle difference, for others, the effect was very large. Player 1 , for example, demonstrated mean ratios of 1.92, 1.25, $1.87,1.29$ on each of the four successive quarter-note beats, thus varying from almost a 2:1 ratio on the first to a 5:4 ratio on the second beat. Player 8 used ratios around 1.5 (3:2) on the strong beat but made the weak beats almost equal.

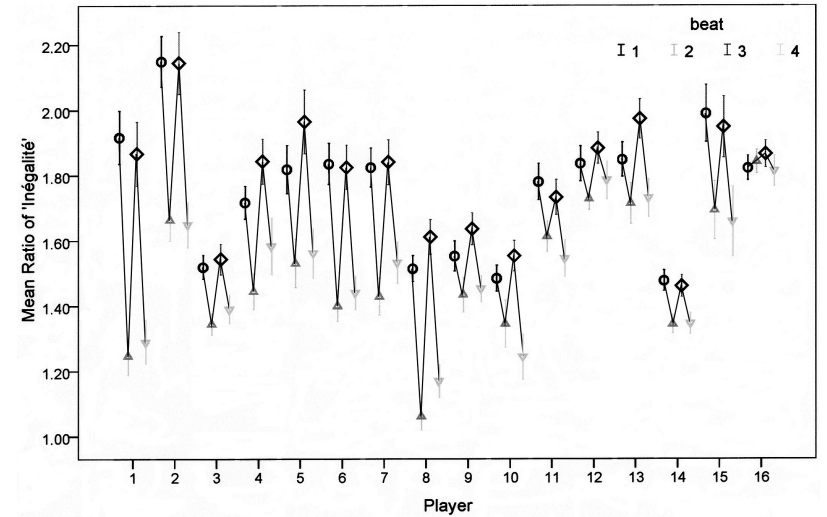

FIGURE 4. Mean ratio of inégalité shown for each performer for each the four quarter note beats in the measure; error bars represent the $95 \%$ confidence interval of the mean.
In Figure 4, it is notable that the ratios at the half bar (third pair) were often higher than those on the first beat of the bar. Indeed, if we compare the overall ratios, we find a significant difference, $F(1,3070)=8.52, p<.01$, between the first $(M=1.76)$ and the third $(M=1.79)$. For the individual performances, we found significant effects for six players, with $F(1,190)$ ranging between 5.11 and 9.56; the effect was significant at a $p<.05$ level for three players and at a $p<.01$ level for the other three players. In all of these cases, the half bar was performed with a larger ratio than the pair starting on the first beat.

Violinists tended to emphasize the difference between strong and weak quarter note beats to a greater extent than the harpsichordists. We examined the ratio between the average of the two strong beats and the average of the weak beats and found a significant difference, with an average ratio of 1.28 for the violinists and 1.10 for the harpsichordists, $F(1,14)=13.97, p<.01$.

The global effect of pitch interval—using the four categories: minor second, major second, third (minor or major), and intervals larger than a third-showed that larger intervals were played more unequal (1.61-1.631.63-1.69). When examining the individual performers, the effect was only significant for five of the 16 subjects, for whom $F(3,398)$ varies between 3.93 and 10.44, which made the difference significant at a $p<.01$ level for three players and at a $p<.001$ level for the other two players. The summaries for these five performers are shown in Figure 5. Interestingly, the effects were very similar for these five performers: differences between minor seconds,

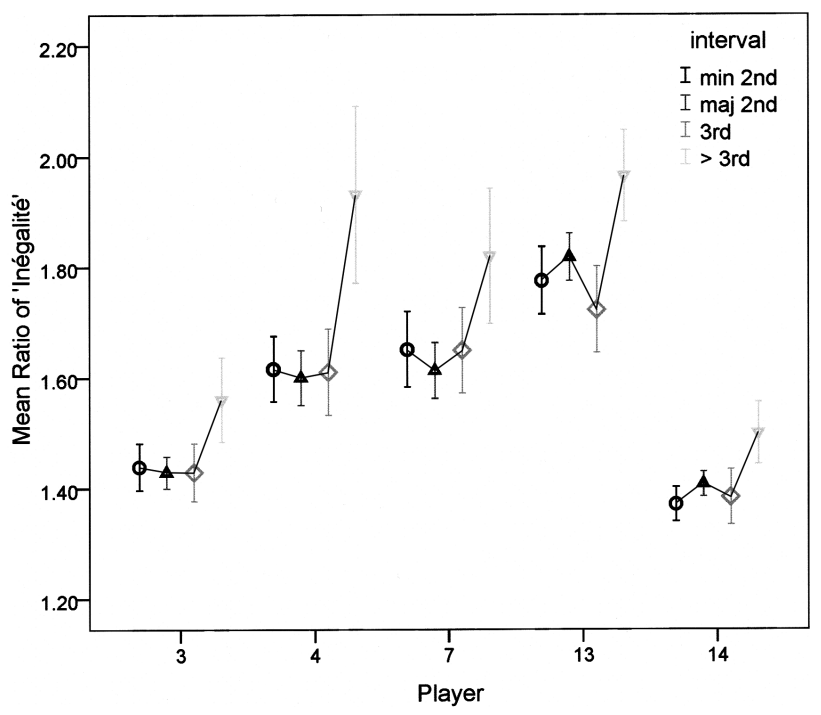

FIGURE 5. Mean ratio of inégalité for four pitch interval categories, shown for five performers who showed a significant effect of pitch interval; error bars represent the $95 \%$ confidence interval of the mean. 
major seconds, and thirds were small, but a significantly larger ratio was used at the larger intervals.

In addition to analysis of the relation between tempo variation and the size of the intervals, interval direction was also examined. The effect of interval direction on the ratios was almost entirely due to only two subjects who made very significant distinctions between descending and ascending intervals: Subject $1(1.50-1.65), F(1,400)=$ $9.45, p<.01$, and Subject $15(1.72-1.93), F(1,400)=17.38$, $p<.001$. For these two performers the effect was significant in each of the three tempo categories, while the other 14 performers showed no effect from interval direction.

\section{Discussion and Conclusion}

Although the intersubject differences were striking, the performers largely agreed on ratios between 1.25 (5:4) and 2.0 (2:1): $70.7 \%$ of the inégale pairs had a ratio between 1.25 and 2.0 ; only $14.8 \%$ had a ratio larger then 2.0 and ratios larger than $3.0(0.3 \%)$ were very scarce. In general, the maximum ratios found seemed relatively small, as historical treatises often recommend a 3:1 average ratio (Houle, 1987). In swing research, Friberg and Sundström (2002) found maximum ratios over 3.5 at similar tempi. When Honing and De Haas (2008) presented jazz drummers a swing pattern with a 2:1 eighth note ratio and asked them to perform it at different tempi, the performed ratios were mostly between 2.0 and 2.5. Thus, the musicians had a tendency to make the ratio larger than the 2:1 of the example pattern. Therefore, the inégalité of current baroque music performance can be characterized as a milder phenomenon than swing in current jazz performance.

The results show that the performers used inégalité as an expressive means according to their personal taste. Individual performers not only demonstrated differences in mean ratio and amount of variability, they also differed in their treatment of structural elements such as the metric position and pitch interval. The most striking difference between performers was found in the relation between inégalité ratio and tempo. However, before discussing this issue, we summarize the effects of musical structure.

Among the structural elements, metric position had the strongest effect on the inégalité ratio. All but one performer used a larger inequality on strong quarter note beats compared to weak beats, but the amount of difference varied. This aspect is not mentioned in historical treatises, which usually describe only one performance strategy for the whole range of unequal notes in a piece. Also, a comparison with jazz research was not possible, since the drummers studied normally only used swing eighths on weak beats. However, it seems logical that the ratio is influenced by the amount of agogic accent the performers want to give to the structurally important notes. We should also note here that we did not find significant differences between the lengths of the strong and the weak quarter note beats, which indicates that the performers used the inégalité ratio to convey the accentuation, lengthening the first, but shortening the second eighth note, rather than just adding time on the first note. The fact that violinists make a larger difference than harpsichordists could be a result of instrument technique. The harpsichord has very limited dynamic possibilities, so phrasing and articulation depends almost entirely on the timing. In fact, one would then expect a harpsichordist to make a greater contrast between stronger and weaker beats, but the opposite was true. This can be explained by an increased cautiousness regarding the timing in harpsichord performance. Violin performance is more dynamic, while the harpsichordists in this experiment prefer a more homogeneous version of the notes inégales, with a more subtle variation of the ratio in relation to the meter.

The link between inégalité and metric position allows us to determine the metric hierarchy of a piece. As an example, the normalized duration-averaged over all performers and tempi - of each note in the first piece is shown in Figure 6. This figure also explains the somewhat surprising finding that the half bar receives more inequality compared to the start of the whole bar. The gavotte typically starts with a half bar upbeat (cf. Figure 1), and here we see clearly that the players mark the start of the piece (and its repeat, event 28) by exaggerating the inequality, and maintain this (to a lesser extent) throughout the piece. This illustrates the upbeat character of the gavotte, in which phrasing always starts in the middle of the bar. It supports the finding that performers increase the length of metrically important notes (cf. Palmer, 1997). The use of notes inégales imposes this type of accentuation at one metric level, but the variations found show the influence of higher metric levels. It must be noted that the differences between stressed and unstressed eighth notes is in general larger and applied more consistently here compared to music that does not ask for notes inégales. In Sloboda's (1983) study, for example, ratios varied between 0.90 and 1.17. Some pianists did lengthen the interonset interval of metrically important notes, but others did not show any effect of metric position.

Only a few performers demonstrated a difference between larger and smaller pitch intervals. Surprisingly, they uniformly used larger ratios at large pitch intervals. This finding contradicts historical sources that indicate 

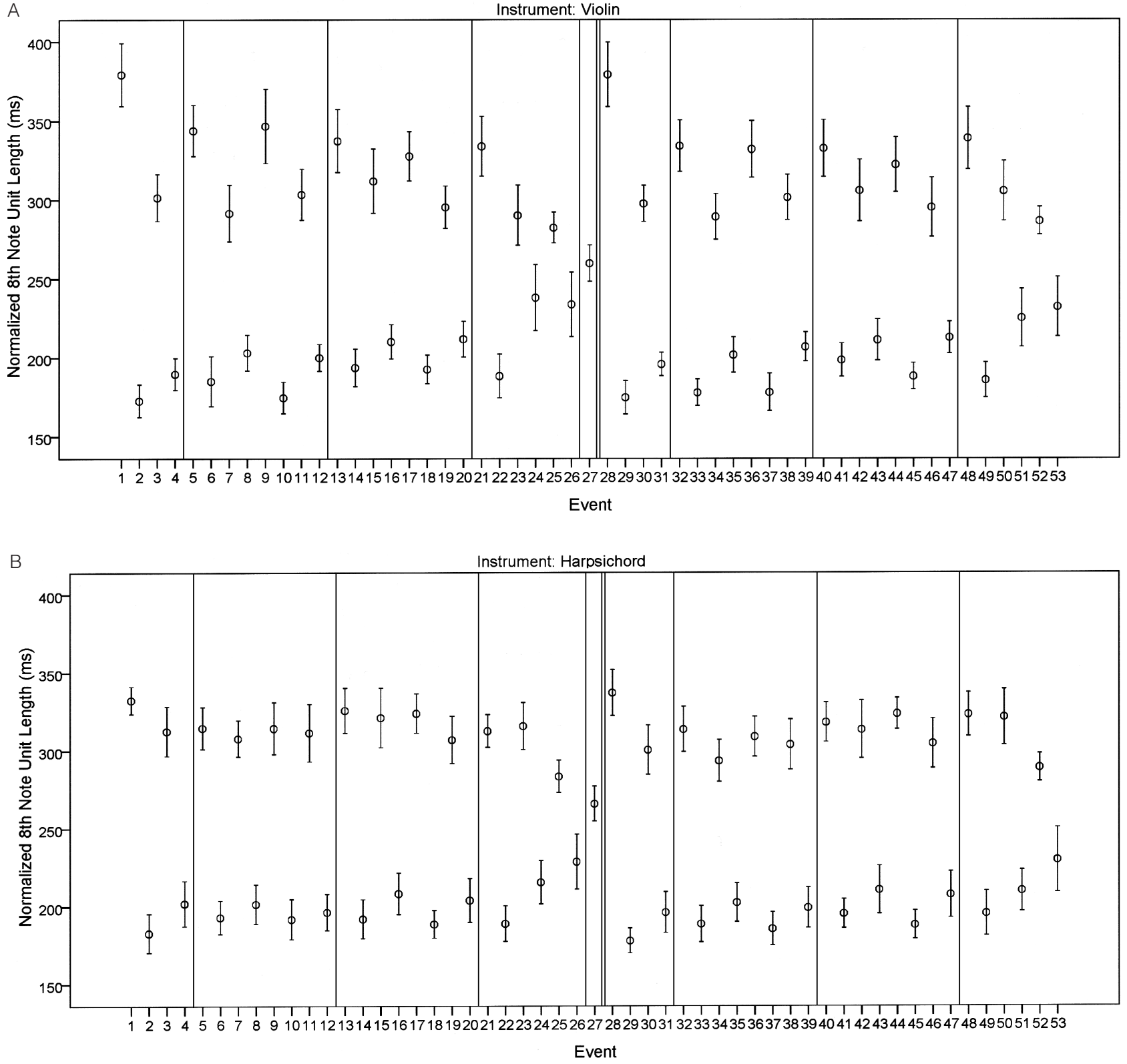

FIGURE 6. Average unit-length (duration of an eighth note) of each event in piece No. 1 (27 events plus 26 from the repeat, as the duration of the final note can not be determined) over all performers and tempi for the eight violinists (above) and the eight harpsichordists (below). The unit length is used here to be able to represent every individual note. Therefore, all note lengths were divided by the number of eighths they contain (so the duration of a quarter note was divided by two, the half note by four). Additionally, they were all normalized to a performance at the middle tempo (MM $=60$ ). Error bars represent the $95 \%$ confidence interval of the mean. Vertical lines represent bar lines and the double vertical line the location of the repeat.

that passages with large pitch intervals should be performed without inégalité (Couperin, 1716/1974). However, it must be noted that the larger pitch intervals used in the present experiment always appear in isolation, whereas the historical sources typically point at passages with large intervals. Often these passages create an effect of polyphony through a streaming effect (cf. Dowling, 1973). At first sight, this effect could be attributed simply to the larger physical distance or the difficulty of playing larger leaps. However, it must be noted that four out of the five performers that showed this effect ranked under the most experienced performers in the group. If the technical difficulty of playing larger intervals were the cause of this effect, we would rather expect to find this effect with less experienced players. Rather, it seems that the five performers who made the ratios of larger 
intervals more substantial tried to ensure that these notes sounded inégale and therefore exaggerated their performance. It seems that these five performers have a common performance strategy that is typical of their style of playing compared to the style of the majority of the performers in this experiment. This conclusion is supported when examining the effect of the direction of the pitch interval. While 14 subjects did not show this effect, two performers showed a highly significant effect in each tempo. Thus, enhancing the inégalité for ascending intervals seems a characteristic feature of their style.

Differences between performers are most obvious when analyzing the relation between the inégalité and the tempo. Not only the magnitude of ratio change, but also the direction differs greatly. The main tendency was to diminish the amount of inequality with increasing tempo, but some performers counter this tendency. The historical evidence on this point is very limited, but Engramelle (1775/1993) reported that larger ratios should be used with an increase in tempo. This would indicate that our minority group was actually in accordance with historical evidence. However, this conclusion has the caveat that the work of Engramelle is more recent than the music investigated here and does not give any specific information on gavottes. Moreover, he stresses the importance of the specific character of each piece much more than the global tempo and does not consequently apply the tempo-ratio relation in his description of timing schemes for the performance of music on mechanical instruments. Here the comparison with jazz swing research is interesting, as three independent studies (Collier \& Collier, 1996; Friberg \& Sundström, 2002; Honing \& De Haas, 2008) show a uniform effect of tempo on the swing ratio. In each of these studies, there was a clear increase of the ratio at slower tempi, which confirms our majority finding. We should note that these studies included tempi that were considerably faster than the ones used here; only Collier and Collier (1996) also included slower tempi, but inconsistent results were reported. Nevertheless, the results of these jazz studies globally show a more uniform effect. It is unclear whether this is due to the relatively small numbers of participants, or because swing is a more standardized type of pattern, allowing less interpretational freedom than notes inégales.

The present results challenge the theory of tempospecific timing (Desain \& Honing, 1994; Honing, 2006; Repp, Windsor, \& Desain, 2002). On the one hand, it is a confirmation that tempo influences expressive timing, but on the other hand, the influence is radically different depending on the performer. This implies that there is no objective tempo-specific timing, but that the relation between tempo and timing rather depends on the personal interpretation of the performers. Performers adapt their timing under the influence of the tempo, but do so according to their personal taste.

One somewhat surprising result is that there was very little difference between specific groups of performers. Gender was not really expected to have a significant influence, but one could have expected a distinction between more and less experienced musicians. A significant difference between the two instruments is only found in the amount of differentiation between strong and weak beats. Here, clear differences were also expected, as the technique of both instruments is completely different. This shows that individual taste and performance style are much more important factors than the technical characteristics of the instruments. Studies of professional music performance are by necessity studies of creative individuals, rather than simple group comparisons. Or at least, the individual creativity and interpretation must be taken into account when generalizing results. This implies that in order to give a representative picture of a certain performance practice, one should use a sufficient number of participants, preferably including subjects of different (educational) backgrounds.

Regarding the origin of inégalité, it has been suggested (Chailley, 1960) that there might be a link with the specific prosody of the French language. Links between language and rhythmic structure in music have been shown to exist (e.g., Patel, Iversen, \& Rosenberg, 2006). Moreover, the link between prosody in poetry and metric structure in music in period thinking is obvious (Houle, 1987). Some of the participants reported that they used language to develop a natural sense of inégalité. An example sentence used in early music pedagogy is "Bonjour monsieur, bonjour madame" [Hello sir, hello madam], which corresponds to a typical iambic pattern found in dances with an upbeat character such as the bourrée. An interesting extension of this research would be to observe whether the ratios found in the present paper could be related to similar patterns in speech, and more specifically in the declamation of poetic texts from the baroque period.

In a study using music from the late 19th and early 20th century, Patel and Daniele (2003a) showed that durational contrast was significantly higher in British music compared to French music, using the normalized pairwise variability index ( $n P V I$; Low, Grabe, \& Nolan, 2000). They found a mean $n P V I$ of 46.9 for British themes and 40.9 for French themes. In speech, the contrast was even larger with 55.0 for British English and 35.9 for continental French (Patel et al., 2006). Huron 
and Ollen (2003) analyzed nPVI in a broader set of melodic themes, including baroque music. They found a much smaller, but still significant difference in $n P V I$ between British (45.6) and French (43.7) music. However, this set includes themes by French baroque composers that should be performed inégale. This could have potentially influenced the results of the study. Comparing score based and performance based $n P V I$ in the pieces from the present study revealed a notable difference, with an average $n P V I$ of 4.2 for the score data against a grand average $n P V I$ over all performers of 55.0 in the recordings. A similar remark could be made about the findings of Patel and Daniele (2003b) on the evolution of $n P V I$ in German music. They found a gradual increase in durational contrast through time, comparing themes from composers born between 1637 and 1895 . However, if inégalité (or related phenomena such as overdotting, Fabian \& Schubert, 2003) should also be applied to German baroque music (cf. supra), results might also change. For a possible explanation for this increase in durational contrast, the influence of Italian music on German music is mentioned (Patel \& Daniele, 2003b). An alternative explanation might be that there is an evolution in the notation policy of composers, where we see a gradual increase in the precision with which the rhythm is notated. A pair of inégales will later be written as a triola or even a dotted figure, thus increasing the score-based $n P V I$. It would, therefore, be of interest to investigate if the differences in durational contrast between nations and time periods remain if we start from the performed durations rather than from the score.

Other possibilities for further research include the use of other instruments (e.g., viola da gamba, traverso), comparisons with other music genres (e.g., more complicated court dances like the allemande or the courante), or an evaluation of listeners' perception (cf. Schubert \& Fabian, 2003) for example, regarding the interpersonal differences in the treatment of timing in different tempo conditions.

Unfortunately, a comparison with real 18th century performance practice is not possible, but it would be interesting to get the opinion of experts in this field of historical performance practice. Musicologists and musicians have been studying the historical treatises extensively, but, to date, data on contemporary performance practices were not available. Do the results from the present experiment entirely comply with historical evidence? Or do some historical sources contradict aspects of contemporary performance?

\section{Author Note}

Correspondence concerning this article should be addressed to Dirk Moelants, IPEM-Dept. of Musicology, Ghent University, Blandijnberg 2, 9000 Ghent, Belgium. E-MAIL: Dirk.Moelants@UGent.be

\section{References}

Arbeau, T. (1588). Orchesographie. Lengres: Iehan des Preyz.

BABitz, S., BYrT J., \& Collins, M. (1967). Three further views on notes inégales. Journal of the American Musicological Society, 20, 473-485.

Boersma, P. \& Weenink, D. (2008). Praat: Doing phonetics by computer [Computer program]. Retrieved October 28, 2008, from http://www.praat.org/

Borrel, E. (1931). Les notes inégales dans l'ancienne musique francaise ['Notes inégales' in French early music]. Revue de Musicologie, 12, 278-289.

ByrT, J. (1996). Writing the unwritable. The Musical Times, 138, $18-24$.

BYRT, J. (2007). Elements of rhythmic inequality in the arias of Alessandro Scarlatti and Handel. Early Music, 35, 609-628.

Chailley, J. (1960). A propos des notes inégales [About 'notes inégales']. Revue de Musicologie, 45, 89-91.

Collier, G., \& Collier, J. (1996). The swing rhythm in jazz. In B. Pennycook \& E. Costa-Giomi (Eds.), Proceedings of the 4th International Conference on Music Perception and
Cognition (pp. 477-480). Montreal, Canada: McGill University.

COUPERIn, F. (1974). L'art de toucher le clavecin [The art of playing the harpsichord] (M. Halford, Trans.). Paris: Alfred Publishing Company. (Original work published 1716)

Desain, P., \& Honing, H. (1994). Does expressive timing in music performance scale proportionally with tempo? Psychological Research, 56, 285-292.

Donington, R. (1967). A problem of inequality. Musical Quarterly, 53, 503-517.

Dowling, W. J. (1973). Perception of interleaved melodies. Cognitive Psychology, 5, 332-337.

Engramelle, M. D. J. (1993). La tonotechnie ou l'art de noter les cylindres ['Tone technique' or the art of marking cylinders]. Paris: Hermann. (Original work published 1775).

Fabian, D., \& Schubert, E. (2003). Expressive devices and perceived musical character in 34 performances of Variation 7 from Bach's Goldberg Variations. Musicae Scientiae, Special Issue 2003-2004, 49-68. 
Friberg, A., \& Sundström, A. (2002). Swing ratios and ensemble timing in jazz performance: Evidence for a common rhythmic pattern. Music Perception, 19, 333-349.

Fuller, D. (2001). Notes inégales. In S. Sadie \& J. Tyrrell (Eds.), The new Grove dictionary of music and musicians (Vol. xviii, pp. 190-200). London: McMillan.

Hefling, S. E. (1993). Rhythmic alteration in seventeenth- and eighteenth-century music. New York: Schirmer Books.

Honing, H. (2006). Evidence for tempo-specific timing in music using a web-based experimental setup. Journal of Experimental Psychology: Human Perception and Performance, 32, 780-786.

Honing, H., \& De HaAs, W.B. (2008). Swing once more: Relating timing and tempo in expert jazz drumming. Music Perception, 25, 471-476.

Houle, G. (1987). Meter in music, 1600-1800. Bloomington, IN: Indiana University Press.

Huron, D., \& Ollen, J. (2003). Agogic contrast in French and English themes: Further support for Patel and Daniele (2003). Music Perception, 21, 267-271.

LitTLE, M. E. (2001). Gavotte. In S. Sadie \& J. Tyrrell (Eds.), The new Grove dictionary of music and musicians (Vol. ix, pp. 591-593). London: McMillan.

LOUlí,, E. (1696). Elements ou principes de musique, mis dans un nouvel ordre [The elements or principles of music reordered]. Paris: Christophe Ballard.

Low, E. L., Grabe, E., \& Nolan, F. (2000). Quantitative characterizations of speech rhythm: Syllable-timing in Singapore English. Language and Speech, 43, 377-401.

Neumann, F. (1965). The French “inégales", Quantz, and Bach. Journal of the American Musicological Society, 18, 313-358.

Neumann, F. (1988). The notes inégales revisited. Journal of Musicology, 6, 137-149.

Newman, A. (1985). Bach and the baroque: European source materials from the baroque and early classical periods with special emphasis on the music of J. S. Bach. Hillsdale, NY: Pendragon Press.

Ornoy, E. (2006). Between theory and practice: Comparative study of early music performances. Early Music, 24, 233-247.

Palmer, C. (1997). Music performance. Annual Review of Psychology, 48, 115-138.

Patel, A. D., \& Daniele, J. R. (2003a). An empirical comparison of rhythm in language and music. Cognition, 87, B35-B45.

Patel, A. D., \& Daniele, J. R. (2003b). Stress-timed vs. syllable-timed music? A comment on Huron and Ollen (2003). Music Perception, 21, 273-276.

Patel, A. D., Iversen, J. R., \& Rosenberg J. C. (2006). Comparing the rhythm and melody of speech and music: The case of British English and French. Journal of the Acoustical Society of America, 119, 3034-3047.

Prögler, J. A. (1995). Searching for swing: Participatory discrepancies in the Jazz rhythm section. Ethnomusicology, 39, 21-54.

Repp, B. H., Windsor, W. L., \& Desain, P. (2002). Effects of tempo on the timing of simple musical rhythms. Music Perception, 19, 565-593.

Rousseau, J.-J. (1772). Dictionnaire de musique [Dictionary of music]. Amsterdam: Marc Michel Rey.

Schmitz, H.-P. (1953). Die Tontechnik des Père Engramelle: Ein Beitrag zur Lehre von der musikalischen Vortragskunst im 18. Jahrhundert [The 'tone technique' of Père Engramelle: A contribution to the theory of musical rhetoric in the 18th century]. Kassel: Bärenreiter.

Schubert, E., \& Fabian, D. (2001). Preference and perception in dotted $6 / 8$ patterns by experienced and less experienced baroque music listeners. Journal of Music Perception and Cognition, 7, 113-132.

SlobodA, J. A. (1983). The communication of musical metre in piano performance. The Quarterly Journal of Experimental Psychology Section A, 35, 377-396. 
